\title{
Strength of rock-like specimens with pre-existing cracks of different \\ length and width
}

\author{
Ivan Gratchev ${ }^{1 *}$, Dong Hyun Kim², and Chong Kit Yeung ${ }^{3}$
}

1) Senior Lecturer, Griffith School of Engineering, Griffith University, Australia. *Corresponding author. Email: ivangratchev@gmail.com

2) PhD candidate, Griffith School of Engineering, Griffith University, Australia

3) Formerly undergraduate student, Griffith School of Engineering, Griffith University, Australia

\begin{abstract}
.
This study seeks to investigate the effects of pre-existing cracks on strength of rocks. Three types of material (A, B, and $\mathrm{C}$ ) were selected to provide a wide range of strength of intact specimens. For Type A, the unconfined compressive strength (UCS) of intact specimens was about $10 \mathrm{MPa}$, for Type B - $45 \mathrm{MPa}$, and Type C - 60 MPa. For each type, pre-existing cracks with different length and width were made, and the specimens were tested in unconfined compression. The data from 76 tests indicated that the influence of cracks was more pronounced for the specimens of Type A, which had a relatively low strength of the intact specimens. It was also found that the width of pre-existing cracks could affect the strength of specimens, especially those of Type A. Different failure patterns, including the coalescence of pre-existing cracks, were observed and discussed.
\end{abstract}

Key words: crack; strength; rock bridge; laboratory test 


\section{Introduction}

Discontinuities play a key role in the failure process of rock and rock mass. Small fractures can decrease the strength of rock while large-scaled joints can have a significant effect on the overall stability of rock mass (Eberhardt et al. 2004). Discontinuities are often separated by intact rocks, which are known as "rock bridges". These rock bridges contribute to the stability of jointed rock mass by providing a strength reserve (Gehle and Kutter 2003) that needs to be broken first before failure can take place. In recent years, a number of experimental studies have been performed to investigate the mechanism of crack propagation in rock-like material under uniaxial (Shen et al. 1995; Wong and Chau 1998; Sagong and Bobet 2002; Xu et al. 2013; Yin et al. 2014; Cao et al. 2015), biaxial (Bobet and Einstein 1998), and shear (Gehle and Kutter 2003) stress conditions. It was revealed that under load conditions, wing cracks first appear at the tips of pre-existing cracks (flaw) while shear cracks typically lead to coalescence and failure. The aforementioned studies also indicated that the process of coalescence was rather complex, and depended on the rock material and geometry of pre-existing cracks.

While the mechanism of crack propagation is relatively well-understood, the extent to which pre-existing cracks can affect the strength characteristics of rocks still remains unclear. Ramamurthy and Arora (1994), Yang et al. (1998), Park and Bobet (2009) noted that the characteristics of joints such as their number and orientation can affect the strength of rock. Shen (1995), Park and Bobet (2009) reported that the joint roughness and the friction of the filled material (Shen 1995; Park and Bobet 2009) can also influence the strength of rock and rock mass. These joint characteristics are considered in the joint strength parameter, which is commonly used in engineering practice (Ramamurthy and Arora 1994; Zhang 2010). Unfortunately, much less attention has been given to the length and width of joints, which are parameters that can also affect the strength of rock and rock mass. This study seeks to address this issue by investigating the effects of pre-existing cracks of different width and length on 
the unconfined compressive strength (UCS) of rock-like material of various strength. This technical note presents and discusses the obtained results.

\section{Experimental program}

Three types of material (A, B, and C) were selected to provide a wide range of strength of intact specimens. Type A was made of the commercially available Bastion concrete mix (a premade concrete mixture complied with the Australian Standard AS3648-1993) to produce intact specimens with a relatively low UCS of about 10-11 MPa. The specimens of Type B were prepared from a mixture of water, cement, and coarse basalt aggregates of 10-mm size. The water/cement ratio of this mixture was 0.42 which resulted in the UCS of intact specimens to be about 45-46 MPa. Similar to Type B, specimens of Type C were made of a mixture of water, cement, and aggregates but with a lower water/cement ratio of 0.29 . The strength of intact specimens of Type C was estimated to be 59-60 MPa.

All specimens were prepared according to the Australia Standard AS1012-1994, and then poured into a cylindrical (100 mm in diameter and $200 \mathrm{~mm}$ in height) mould. Foam sheets with the length of either $50 \mathrm{~mm}$ or $70 \mathrm{~mm}$ were fitted in the top and bottom parts of the mould to produce pre-existing cracks in the specimens (Fig. 1). Two pre-existing cracks with a length of $70 \mathrm{~mm}$ each formed a "short” rock bridge (Fig. 1a) while the 50-mm long cracks created a “long” rock bridge (Fig. 1b). To produce cracks of different width, sheets of different thickness of either $1 \mathrm{~mm}, 3 \mathrm{~mm}$ or $5 \mathrm{~mm}$ were used.

The concrete mixture was stored in the mould for 24 hours before de-moulding, and then placed in a curing tank for 7 days at a temperature of $24^{\circ}$. After 7 days, the specimens were removed from the curing tank, fan-dried for 3 hours and tested in unconfined compression. A compression load was applied with an increment of $2.6 \mathrm{kN}$ per second until the specimen failed (AS 1141-1996). A high-speed camera was used to record the behaviour of the specimen 
throughout the test. In total, 78 specimens were tested; each test with pre-existing cracks was repeated 4 times and the average value was used. The test conditions are summarized in Table 1.

\section{Results and discussion}

\subsection{Unconfined compression tests}

Results from unconfined compression tests on the specimens of Type B with and without preexisting cracks are plotted in Fig. 2 to demonstrate a typical stress-stain behavior observed in this study. As can be seen in this figure, the intact specimen exhibits a higher stress at failure (46.6 $\mathrm{MPa}$ ) compared to the specimens with the pre-existing cracks. It is interesting that the specimen with pre-existing cracks of 1-mm wide reached almost the same value of stress (44.6 $\mathrm{MPa}$ ) as the intact specimen. However, the specimens with wider cracks (3 $\mathrm{mm}$ and $5 \mathrm{~mm}$ ) were observed to have much lower strength of 35.6 MPa and 31.9 MPa, respectively.

To better understand the effect of the crack properties, all data from unconfined compression tests on specimens of Type A (a), Type B (b) and Type C (c) were plotted in Fig. 3 in the form of the stress at failure against the width of pre-existing cracks. It is evident from this figure that regardless of the type of material, the specimens with a longer rock bridge have a higher strength. However, for the specimens of Types A and B, when the width of the pre-existing cracks was only $1 \mathrm{~mm}$, the effect of the bridge length on the strength of specimens was found to be insignificant. These results suggest that the effect of the bridge length may also be material-dependent and it can become more pronounced as the strength of intact specimens (Type C) increases.

The results in Fig. 3 also indicate that an increase in the crack's width decreases the strength of specimens. To estimate the influence of a crack's width on different types of specimens, the laboratory data were re-plotted in Fig. 4 in terms of the strength reduction (which is defined as 
the ratio between the strength of the specimen with pre-existing cracks and the strength of the intact specimen) against the width of pre-existing cracks. This figure suggests that the extent to which the width of pre-existing cracks can influence the behavior of specimens in unconfined compression depends on the strength of intact specimens. For example, for the specimens with a higher strength (Type C), a relatively small reduction in the strength (about $30 \%$ ) was observed as the width of crack increased from $1 \mathrm{~mm}$ to $5 \mathrm{~mm}$. In contrast, there was a significant drop in the strength of specimens of Type A (almost 90\%) as the width of preexisting cracks increased from 1 to $5 \mathrm{~mm}$. It is noted that such a large decrease in the strength occurred in specimens of Type A with both long and short rock bridges (Fig. 4).

\subsection{Failure patterns}

Visual observations during testing revealed some similarities in the failure pattern of specimens with different characteristics of pre-existing cracks. For most of the specimens, it was a shear crack that appeared at the tip of the top pre-existing crack as shown in Fig. 5b. This shear crack then propagated in a stable manner through the rock bridge (Fig. 5c), causing the failure of the specimen. There were a few cases recorded when the coalescence of the top and bottom pre-existing cracks (Fig. 5d) occurred during loading.

Figure 6 summarizes the most common failure patterns, which were observed for all three types of specimens. The failure pattern shown in Fig. 6a,b involved the coalescence of preexisting cracks, and it was primarily found in the specimens with the short bridge. In contrast, the failure patterns shown in Fig. 6c,d were mostly observed in the specimens with the long rock bridge. This failure mode was characterized by the shear failure that occurred without the coalescence of the pre-existing cracks. As can be seen in Fig. 6c,d, the shear crack propagated through the rock bridge at an angle, resulting in failure. 


\section{Conclusions}

In this work, the effect of pre-existing cracks of different length and width on the strength of rocks was studied using three types (Type A, B, and C) of specimens. The following conclusions can be drawn:

- Regardless of the type of specimens, the longer rock bridge was associated with a higher stress at failure. However, for specimens of Type A and B with a crack width of $1 \mathrm{~mm}$, the influence of rock bridge length was found to be insignificant.

- The width of pre-existing cracks had a significant effect on the strength of specimens. The strength of specimens of all three types decreased as the crack's width increased from $1 \mathrm{~mm}$ to $5 \mathrm{~mm}$; however, this effect was more pronounced in the specimens with a relatively low strength of the intact specimens (Type A).

- For most of the specimens, failure was caused by a shear crack, while the coalescence of the pre-existing cracks was mostly observed in the specimens with the short rock bridge.

\section{Reference}

AS 1012-1994 (1994) Methods of testing concrete. Method 2: Preparation of concrete mixes in the laboratory

AS 1141-1996 (1996) Methods for sampling and testing aggregates. Method 51: Unconfined compressive strength of compacted materials

AS 3648-1993 (1993) Australian Standard Specification and Methods of Test for Packaged Concrete Mixes

Bobet A, Einstein H (1998) Fracture coalescence in rock-type materials under uniaxial and biaxial compression. Int J Rock Mech Min Sci 35(7): 863-888

Cao P, Liu T, Pu C, Lin H (2015) Crack propagation and coalescence of brittle rock-like specimens with pre-existing cracks in compression. Engineering Geology 187: 113-121 
Eberhardt E, Stead D, Coggan JS (2004) Numerical analysis of initiation and progressive failure in natural rock slopes - the 1991 Randa rockslide. Int J Rock Mech Min Sci 41: 69-87

Gehle C, Kutter HK (2003) Breakage and shear behaviour of intermittent rock joints. Int J Rock Mech Min Sci 40: 687-700

Park CH, Bobet A (2009) Crack coalescence in specimens with open and closed flaws: A comparison. Int J Rock Mech Min Sci 46 (5): 819-829

Ramamurthy T, Arora VK (1994) Strength prediction for jointed rocks in confined and unconfined states. Int J Rock Mech Min Sci 31(1): 9-22

Sagong M, Bobet A (2002) Coalescence of multiple flaws in a rock-model material in uniaxial compression. Int J Rock Mech Min Sci 39: 229-241

Shen B (1995) The mechanism of fracture coalescence in compression-experimental study and numerical simulation. Eng Fract Mech 51 (1): 73-85

Shen B, Stephansson O, Einstein HH, Ghahreman B (1995) Coalescence of fractures under shear stress experiments. J Geophys Res 100 (B4): 5975-5990

Wong RHC, Chau KT (1998) Crack coalescence in rock-like material containing two cracks. Int J Rock Mech Min Sci 35 (2): 147-164

Xu T, Ranjith PG, Wasantha PL, Zhao J, Tang CA, Zhu WC (2013) Influence of the geometry of partially-spanning joints on mechanical properties of rock in uniaxial compression. Engineering Geology 167: 134-147

Yang ZY, Chen JM, Huang TH (1998) Effect of joint sets on the strength and deformation of rock mass models. Int J Rock Mech Min Sci 68: 66-84

Yin P, Wong RH, Chau KT (2014) Coalescence of two parallel pre-existing surface cracks in granite. Int J Rock Mech Min Sci 35(1): 75-84

Zhang L (2010) Estimating the strength of jointed rock masses. Rock Mech Rock Eng 43: 391402 


\section{Figure captions}

Figure 1. Specimens with pre-existing cracks that form a short rock bridge (a), and a long rock bridge (b).

Figure 2. Stress-strain curves of the specimens of Type B including the intact specimen and specimens with pre-existing cracks of 1,3 , and 5 mm wide.

Figure 3. Results from unconfined compression tests on specimens with short and long rock bridges: a) Type A, b) Type B, and c) Type C.

Figure 4. Strength reduction vs the width of pre-existing cracks obtained for specimens with a short rock bridge (a), and a long rock bridge (b).

Figure 5. Initiation and propagation of cracks in the specimen under unconfined compression.

Figure 6. Failure patterns observed in specimens. 